\title{
Integrated Solar Thermochemical Reaction System
}

\begin{tabular}{|c|c|c|}
\hline \multicolumn{2}{|c|}{$\begin{array}{l}\text { PACIFIC NORTHWEST } \\
\text { NATIONAL LABORATORY }\end{array}$} & 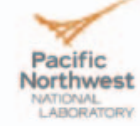 \\
\hline PROGRAM: & SunShot CSP R\&D 2012 & \\
\hline TOPIC: & Advanced Power Cycles & \\
\hline LOCATION: & Richland, Washington & \\
\hline $\begin{array}{l}\text { AWARD } \\
\text { AMOUNT: }\end{array}$ & Up to $\$ 3.5$ million & \\
\hline PROJECT TERM: & 2012-2014 & \\
\hline
\end{tabular}

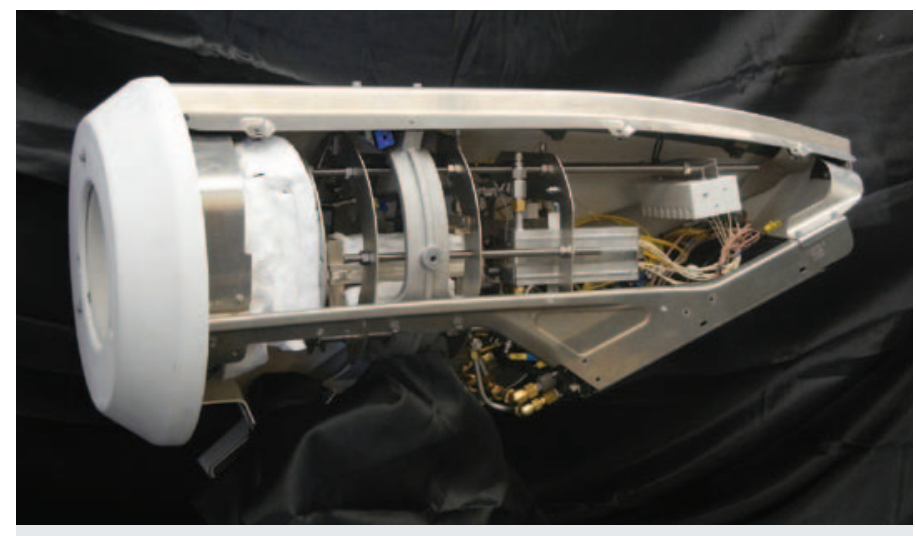

Pacific Northwest National Laboratory is developing a prototype solar thermochemical reaction system. Photo from Pacific Northwest National Laboratory

\section{CONTACTS}

Project Leader:

Mr. Robert Wegeng robert.wegeng@pnl.gov
Partnering Organizations:

- BARR Engineering

- Diver Solar, LLC

- Oregon State University

\section{MOTIVATION}

Concentrating solar power (CSP) systems that are hybridized with natural gas plants offer logistical, economical, and environmental benefits. Natural gas combined cycle (NGCC) power plants are already well developed at high efficiency and can be constructed with relatively low capital costs, compared to other power-generation options. In addition, these hybridized plants are capable of operating around the clock, regardless of the availability of sunlight and do not require energy storage.

\section{PROJECT DESCRIPTION}

The research team is working to develop and demonstrate a high-performance solar thermochemical reaction system in an end-to-end demonstration that produces electricity. Advancing the current technology readiness level from proof of concept to validated prototype, the researchers are improving the solar thermochemical reaction system performance and establishing baseline costs for the design and manufacturing methods.

\section{IMPACT}

This approach provides significant benefits compared to alternative CSP concepts. A highly efficient solar thermochemical reaction system would allow for 24-hour operation without the need for storage technology, and reductions in total system costs while providing a relatively low-risk deployment option for CSP systems.

For more information, visit the project page at: www.solar.energy.gov/sunshot/csp_sunshotrnd_pnnl.html. 